\title{
O uso da tradução no ensino-aprendizagem das línguas estrangeiras
}

\author{
Sergio Romanelli (ROMANELLI, Sergio) \\ Professor Doutor da Universidade Federal de Santa Catarina - UFSC \\ sergioroma70@gmail.com
}

\section{Resumo}

Com o surgimento da Abordagem Comunicativa, em meados dos anos 1980 do século passado, a questão do uso da tradução em sala de aula de língua estrangeira (LE) foi deslocada para as áreas periféricas do debate linguístico. Os manuais de linguística aplicada e de didática das LE ignoraram durante muito tempo a questão, considerando-a um problema já resolvido, ou seja, era comumente aceito pela comunidade científica que o uso da tradução em sala de aula era desnecessário e até desaconselhável. Com este artigo, pretende-se reabrir a discussão analisando os motivos não somente linguísticos, mas também ideológicos e políticos que essa discussão envolve, e reavaliar as vantagens desta técnica didática. Começa-se ilustrando de que forma as várias abordagens para o ensino de LE têm considerado a tradução desde meados do século XVII até a época contemporânea. Verifica-se como, não obstante a tradução tenha perdido progressivamente seu papel de técnica eficaz no ensino/aprendizagem de uma LE, é, porém, bastante comum ver professores que usam a língua materna (LM), e estudantes que se aproximam da LE mediante o uso da tradução. Conclui-se esta análise sugerindo uma série de possíveis atividades didáticas que contemplem o uso da tradução em uma sala de aula de LE.

Palavras-chave: tradução, linguística aplicada, ensino de línguas estrangeiras.

\begin{abstract}
With the advent of the Communicative Approach, in the mid 1980s, the issue of the use of translation in foreign language classes was moved to the periphery of the linguistic debate. For a long time, Applied Linguistics and foreign language teaching handbooks ignored the matter as a given. That is, the scientific community simply accepted that working with translation in the classroom is unnecessary and even inadvisable. The article intends to readdress this issue, taking into account not only linguistic, but ideological and political factors involved in this discussion, and also to re-evaluate the advantages of translation as a didactic technique. Initially, the article traces the ways in which foreign language teaching has approached translation since the seventeenth century. The article also demonstrates that, despite the fact that translation has gradually lost ground as an effective technique for teaching a foreign language, teachers still often resort to the mother tongue, and
\end{abstract}


students often approach the foreign language they study by way of translation. The article concludes with a series of didactic activities that contemplate the use of translation in the foreign language classroom.

Keywords: translation, applied linguistics, foreign language teaching.

\section{Traduzir: ou seja, a arte de aprender a compreender}

Não parece aqui necessário, no contexto deste artigo, dar uma definição do que é tradução, exercício intelectual em que muitos teóricos, letrados e linguistas já se debruçaram insistentemente durante séculos; mas sim, ilustrar o seu uso e sua importância na didática em geral e, de forma mais específica, na didática das línguas estrangeiras. Para este fim, se fará referência à experiência extraordinária de um educador ante litteram, o francês Joseph Jacotot, e à sua aventura intelectual, como a define Jacques Rancière nas páginas do livro, Le Maître Ignorant.

Rancière elucida de forma brilhante o percurso deste revolucionário exilado e leitor de Literatura Francesa na Universidade de Louvain, que em 1818 espalhou o terror no mundo acadêmico europeu. Sua heresia foi a de ter ensinado Literatura Francesa para estudantes flamengos sem ter dado a eles sequer uma aula e sem conhecer sua língua. Convidado para lecionar Literatura Francesa em Louvain, Jacotot teve que enfrentar uma dificuldade aparentemente insuperável: os seus estudantes não conheciam uma palavra sequer de francês e ele ignorava o flamengo. Como atender às expectativas dos seus estudantes e da instituição que o hospedava? Como encontrar um mínimo denominador comum entre ele e os seus alunos, entre algo que tanto ele quanto os seus alunos ignoravam? A solução lhe foi sugerida pela publicação de uma edição bilíngue das Aventuras de Telêmaco: ${ }^{1}$ pediu aos seus estudantes que aprendessem, auxiliados pela tradução, o texto em francês, que repetissem, uma vez chegados na metade do primeiro livro, tudo aquilo que tinham até então aprendido e, finalmente, que lessem a outra parte do romance para contála. No fim, propôs que colocassem por escrito em língua francesa o que achavam do texto que tinham acabado de ler.

\footnotetext{
${ }^{1}$ Romance pedagógico de Fénelon (1651-1715), escritor e moralista francês, inspirado em princípios de tolerância e moderação, que antecipa muitos temas do Iluminismo e inaugura a prosa poética.
} 
Jacotot esperava, desta didática improvisada, por resultados desastrosos, mas ficou positivamente surpreso quando descobriu que seus alunos, abandonados a si mesmos, tinham conseguido superar uma tarefa tão difícil. Ele não havia passado para eles nenhuma noção preliminar da língua francesa, não havia lhes explicado nem a ortografia, nem as conjunções; sozinhos eles tinham buscado equivalências entre palavras francesas e flamengas e tinham deduzido as regras das suas desinências - sozinhos tinham aprendido o seu mecanismo de funcionamento e como associá-las para formar frases. $\mathrm{Na}$ medida em que progrediam na leitura do livro, aumentava a precisão da gramática e da ortografia.

Mas então, deve ter-se perguntado Jacotot, as explicações do docente são supérfluas? O discente tem como aprender e compreender sozinho a estrutura de uma língua sem a ajuda e, principalmente, sem as explicações do seu mestre? Jacotot deve ter achado que a experiência dos seus alunos não era muito diferente da de uma criança que aprende as palavras da LM; ela também, assim como os seus alunos, aprende, usa e domina melhor aquelas palavras que nenhum mestre lhe ensina e que ninguém lhe explica.

A extraordinária descoberta de Jacotot tinha completamente revolucionado suas concepções pedagógicas, aquelas de sua época e até as nossas. A verdade excepcional era que seus estudantes tinham aprendido a falar e a escrever em francês sem a ajuda das suas explicações; ele os tinha "abandonado" com o texto de Fénelon, uma tradução não interlinear como era costume na época, e com sua vontade de aprender o francês. O acaso, ou a necessidade, o tinham obrigado a excluir deste processo de aprendizagem a sua inteligência mediadora, e sem saber, ou querer, Jacotot havia descoberto junto com eles que: “[...] todas as frases e, por conseguinte, todas as inteligências que as produzem são da mesma natureza. Compreender não é mais do que traduzir, isto é, fornecer o equivalente de um texto, mas não sua razão" (RANCIÈRE, 2005, p. 26).

Para falar do Telêmaco de Fénelon os estudantes de Jacotot não tinham nenhuma outra referência além das palavras do Telêmaco; as frases do seu autor eram então suficientes para compreender e expressar aquilo que tinham compreendido, para traduzir sua compreensão. Traduzir, neste caso, significa a capacidade de dizer o que se pensa com as palavras de outro. Os estudantes flamengos puderam fazer isso, pois a escrita de Fénelon já era uma 'tradução': 
Fénelon havia traduzido para o francês uma tradição não homogênea que ia do grego de Homero ao latim de Virgílio e às línguas de outros textos; da mesma forma, os estudantes flamengos haviam aplicado o referido processo intelectual a esta dupla tradução, para explicar com frases do livro francês o que pensavam acerca dele. Na base de sua aprendizagem e de sua compreensão, isto é, de duas formas diferentes de expressar, conforme Rancière, um único ato tradutório, existia uma só inteligência. A inteligência que os tinha guiado para a aprendizagem do francês mediante as palavras do Telêmaco era a mesma com que tinham aprendido a LM. O mecanismo era igual, um mecanismo que remete ao usado hoje para descrever um processo de aquisição de uma LE: observação, armazenamento, repetição e testagem e, especialmente, associação entre o novo e o que já se conhece, uso e reflexão sobre o que se acabou de aprender.

Esta experiência excepcional surpreende, pois contém e antecipa, de uma maneira totalmente involuntária, temas, discussões, polêmicas que virão à tona somente um século depois, no âmbito da Didática, da Linguística e, particularmente, da Linguística Aplicada: educar ou ensinar? Aquisição ou aprendizagem? Traduzir ou não traduzir? Sistematizar ou comunicar? Guiar ou tornar os estudantes autônomos?

O que mais parece formidável na experiência de Jacotot é, notadamente, a importância que assumem, no processo de aprendizagem, a vontade e a inteligência - a motivação, a chamaremos hoje - de quem aprende, e o papel indispensável de um mestre, mas não de um mestre deus ex machina que sabe tudo e que explica tudo, mas de um mestre que facilita, ou emancipa.

Jacotot indicara um caminho aos seus estudantes do qual ignorava as possíveis saídas. Eles encontraram o método: aprender alguma coisa, uma estrutura, uma regra, e a esta associar, comparar, todo o restante; era significativo que tivessem chegado a conhecer o que ignoravam mediante uma tradução. Um fato não pouco relevante se pensarmos no grande preconceito desde sempre sofrido pela tradução em âmbito teórico, desde o método da gramática e da tradução. A tradução, processo já por si só duplo, múltiplo, associativo, comunicativo, havia proporcionado o contato entre o conhecido e o desconhecido, havia revelado aos estudantes flamengos a existência de um substrato comum que engloba e supera, ao 
mesmo tempo, todas as línguas, havia lhes revelado como encontrar a lógica no arbitrário.

Considerando os resultados de Jacotot, nos perguntamos então se é realmente tão inútil (ou pouco natural) usar a tradução no ensino de uma LE. Existem formas, técnicas e estratégias eficazes que podem ajudar os estudantes contemporâneos a descobrir, assim como acontecera aos seus antecessores flamengos, um método para aprender o que ignoram?

\section{Definições e diferenças: abordagem, método e técnica}

Numerosos linguístas já tentaram responder a esta pergunta. Antes de empreender um breve excursus acerca do valor dado à tradução, como técnica didática, por parte dos vários métodos ou abordagens que se desenvolveram na Linguística Aplicada ao ensino das línguas estrangeiras, desde o século passado até hoje, parece oportuno definir rapidamente a diferença existente entre técnica, abordagem e metodologia, frequente e erroneamente confundidas.

A ação da didática das línguas se articula em três níveis: abordagem, método e técnica. Balboni (1998) distingue entre Glottodidattica e Glottodidassi: ${ }^{2}$ uma é a pesquisa teórica acerca da educação linguística, a outra a busca de modelos operativos. A Glottodidattica reflete sobre a teoria da educação linguística, sobre as abordagens e os métodos; enquanto a Glottodidassi se ocupa das técnicas e do uso das glototecnologias. A teoria da educação linguística consiste na reflexão sobre a natureza epistemológica e os fins da educação lingüística, e a respeito da relação entre esta e o conjunto das ciências da educação, da linguagem e da psicologia.

A abordagem é uma teoria da educação linguística, ou seja, uma teoria que descreve o modo para 'aproximar' um discente de uma dimensão específica da educação linguística (língua materna, segunda, estrangeira, étnica, clássica): individualiza as finalidades da educação linguística, indica os objetivos glotodidáticos e propõe métodos para alcançar as finalidades e os objetivos. Uma

\footnotetext{
${ }^{2}$ Optamos por deixar as definições em língua italiana, pois são peculiares da teoria italiana sobre o ensino/aprendizagem das línguas estrangeiras.
} 
abordagem se considera fundada ou infundada com base na teoria da qual assumiu os princípios, na coerência interna e na capacidade de gerar métodos.

O método é o nível que permite a passagem da Glottodidattica para a Glottodidassi: é um conjunto de princípios metodológico-didáticos que traduz uma abordagem em modelos operativos, em material didático, em modalidades de uso das tecnologias didáticas. É adequado ou inadequado em relação à abordagem que pretende realizar. Sua tarefa essencial é a seleção das técnicas glotodidáticas

Uma técnica traduz as indicações do método em atos didáticos. É uma atividade criativa, baseada nos problemas a serem resolvidos usando a língua estrangeira; é um exercício de manipulação, que visa mais a fixação que o uso da língua. Consideram-se as técnicas coerentes ou incoerentes em relação ao método e à abordagem, e eficazes ou ineficazes em relação aos objetivos didáticos.

\section{A tradução como técnica didática segundo as várias abordagens}

No ensino das línguas clássicas ocidentais, a tradução era considerada um instrumento metodológico fundamental e era o centro da Abordagem Formalística e do Método da Gramática e da Tradução, que dominou a escola italiana até os anos 1970. Este método nasceu no Renascimento, especificamente, para o ensino do grego e do latim; pretendia ensinar a LE mediante a LM, isto é, dando todas as explicações necessárias na LM para que o discente desenvolvesse as quatro habilidades canônicas (falar, compreender, escrever e ler). A memorização de listas de palavras e a tradução de textos literários desenvolviam um papel central. Tratavase então de uma abordagem dedutiva que enfatizava a forma escrita da língua. A teoria de referência era a Linguística Descritiva de acordo com a qual a educação consistia no respeito das regras para se chegar, graças a elas, ao domínio dos comportamentos. O discente era considerado uma tabula rasa e o docente o modelo, o juiz que lhe ditava as regras. A língua era nada mais que um conjunto de regras dentro de uma cultura meramente literária e clássica; as principais técnicas didáticas, como já foi mencionado, eram a tradução, o ditado e os exercícios de manipulação. 
Sucessivamente, por causa de um uso exagerado, a tradução foi gradativamente excluída da didática das línguas estrangeiras. Com o aparecimento da Abordagem Direta (ou Método Direto) de Berlitz, o uso da tradução na sala de aula diminuiu. De acordo com esta abordagem, o ensino e a aprendizagem da LE deveriam acontecer mediante o uso exclusivo da LE, não utilizando nunca a LM e a tradução, devendo-se, portanto, transmitir o significado dos enunciados com gestos e imagens. Tratava-se de uma abordagem indutiva que dava muita ênfase à comunicação oral. Esta abordagem não possuía nenhuma referência teórica explicita, o foco de seu interesse era a parole, a língua em uso. Buscava estimular a autonomia do discente guiado por um docente rigorosamente nativo. A língua era um instrumento de comunicação que continha implicitamente modelos culturais que se deveria deixar emergir espontaneamente. Baseava-se em aulas extemporâneas cuja técnica principal era a conversação com o docente nativo sem o uso de materiais específicos.

A tradução como técnica didática voltou a ser usada, ainda que parcialmente, com a Abordagem para a Leitura (Reading Method) que se desenvolveu nos Estados Unidos nos anos 1930 do século XX, quando a língua se tornou, sobretudo, um instrumento necessário para ler obras científicas e literárias estrangeiras. Esta abordagem, que para a aprendizagem da gramática se servia, em algumas ocasiões, de exercícios de tradução, não possuía nenhuma teoria de referência, estava caracterizada por um percurso fortemente indutivo e deixava o estudante muito autônomo de modo que induzisse regras do que lia. O docente era somente um guia, a língua deveria ser um instrumento de comunicação autêntico e a cultura da língua estrangeira não era relevante. Os modelos operativos principais eram aulas e técnicas didáticas como a leitura e a tradução de textos impressos.

Com o ASTP (Army Specialised Training Program) se verificou uma verdadeira revolução copernicana na Glottodidattica. Esta abordagem surgiu durante a segunda Guerra Mundial e considerava a tradução como parte integrante da Análise Contrastiva, em sua versão forte. ${ }^{3}$ As teorias de referência desta abordagem eram a Linguística Estrutural Taxonômica de Bloomfield e a Psicologia Neocomportamentalista de Skinner tanto indutivo quanto dedutivo: o estudante era

\footnotetext{
${ }^{3} \mathrm{O}$ termo 'versão forte' diz respeito à Análise Contrastiva desenvolvida por Krashen, para comparar os sistemas fonológico, lexical, sintático e cultural das duas línguas envolvidas no ensino/aprendizagem, visando a prever os erros dos estudantes.
} 
o protagonista da sua aquisição, mas deveria ser motivado pelo docente. $\mathrm{Na}$ verdade, em sua versão originária, esta abordagem previa a presença de até três docentes: um nativo, um americano, e um dos assim chamados area studies. A língua era um instrumento de comunicação e a cultura tinha um papel fundamental. Os modelos operacionais eram aulas, conversações e primeiras tentativas de problem solving. As principais técnicas didáticas eram traduções e roleplay, e, pela primeira vez, esta abordagem introduzia o uso de filmes e gravações em LE com a contribuição de ferramentas tecnológicas, como o radio e o gravador para fita cassete.

A Abordagem Estrutural ou Áudio-oral, decorrente do ASTP, abandonou todos os aspectos culturais e comunicativos. As teorias de referência também eram a Linguística Estrutural Taxonômica de Bloomfield e a Psicologia Neocomportamentalista de Skinner. No entanto, previa um percurso meramente dedutivo que visava à criação de mental habits; considerava o estudante uma tabula rasa e o docente tinha a tarefa de gerenciar o laboratório linguístico e de corrigir os exercícios escritos; a língua era um conjunto de regras e a cultura pouco relevante. O modelo operacional eram aulas breves, com séries de exercícios estruturais em um laboratório linguístico.

A tradução, já escassamente considerada pelas duas últimas abordagens, ou de qualquer forma, com um papel sempre menos relevante, foi, em seguida, definitivamente excluída e criticada pela Abordagem Comunicativa. Esta abordagem deu origem a vários métodos: um deste foi o Método Situacional, surgido no fim dos anos 1950, em que as línguas voltavam a desenvolver um papel instrumental, comunicativo. O Método Situacional se impôs nos anos 1960-70 e tinha como teoria de referência a Antropolinguística (Malinowsky e Firth), a Sociolinguística de Fishman, a Linguística e a Antropologia contrastivas de Lado, a Pedagogia Ativista (Dewey) e as metodologias da unidade didática e do problem solving. Esta abordagem seguia um percurso principalmente dedutivo, mas com uma indução e uma aprendizagem autônomas do estudante que participava ativamente deste processo; o docente era uma figura intermédia entre um guia, tutor e juiz, a língua era uma realidade formal, mas também um meio de comunicação, e a cultura se tornava sempre mais importante. O modelo operacional era a unidade didática com um currículo descrito em termos morfossintáticos e situacionais; 
utilizava técnicas didáticas de compreensão e de interação com pattern drill e exercícios gramaticais. Excluía definitivamente a tradução e o ditado.

O segundo método originado pela Abordagem Comunicativa foi o NocionalFuncional que introduziu os atos linguísticos, universais presentes em toda língua (saudar, agradecer, etc.). As suas teorias de referência eram a Sociolinguística e a Pragmalinguística (Hymes) e o conceito de competência linguística. Caracterizavase por um percurso sempre mais indutivo que colocava o estudante ao centro do processo e as suas necessidades ao centro do currículo. $\mathrm{O}$ docente se tornou um guia, um tutor, a língua era um meio de comunicação, de ação social, em que prevalecia o valor pragmático sobre a correção formal e a cultura era relevante para comunicar de modo eficaz. O modelo operacional era a unidade didática baseada no problem solving.

Outros métodos, além dos dois citados, se originaram da Abordagem Comunicativa: o Método Natural de Krashen ${ }^{4}$; o Total Physical Response, o Community Language Learning e o Silent Way; ${ }^{5}$ a Sugestopedia ${ }^{6}$ (o único, dentre estes últimos, a retomar em consideração a tradução como técnica didática) e finalmente a Abordagem Comunicativo-Formativa da tradição italiana. ${ }^{7}$

\section{Uma reconsideração: a tradução como quinta habilidade}

Todas as abordagens e os métodos considerados no parágrafo anterior teriam devido, ou querido, ao menos nas intenções, realizar o objetivo principal da

\footnotetext{
${ }^{4}$ Desenvolveu-se nos anos 1980. Considerava as características da pessoa e a inteligência emocional fundamentais na Glottodidattica. A Second Language Acquisition Theory de Krashen originou uma vertente psicológica e psicolinguistica inovadora. Tinha como teorias de referência a Psicodidática, a Psicologia Relacional, os estudos sobre inteligência emotiva e a aquisição em idade precoce, as pesquisas sobre interlíngua e a ordem natural de aquisição.

${ }^{5}$ Algumas variantes americanas definidas por Titone (1982) de métodos clínicos que surgiram nos anos 1960-70 nos Estados Unidos com forte componente psicológica.

${ }^{6}$ Nasceu nos anos 1960-70 na Bulgária (Lozanov). Segundo Titone (1982), era o método clínico por excelência.Tinha como teorias de referência os estudos sobre sugestão, Psicologia Afetiva e da Percepção, e Psicologia Relacional. Os seus modelos operacionais eram aulas que se expandiam também para a vida doméstica do estudante e utilizava como técnicas didáticas a leitura, a escuta e a tradução conduzidas de forma tradicional em um ambiente de training autógeno, com musicoterapia e músicas escritas ad hoc.

${ }^{7}$ Nos anos 1970-80, Renzo Titone, Nereo Perini e Giovanni Freddi realizaram uma síntese entre a abordagem comunicativa pragmática inglesa e a tradição psicopedagógica italiana. Desde os anos 1990, a Glottodidattica italiana opera no âmbito do comunicativo-formativo com uma atenção particular com aos problemas formativos, educativos, psicodidáticos ao lado dos pragmáticos.
} 
educação linguística, isto é, melhorar com as técnicas oportunas as habilidades linguísticas dos estudantes; mas quais e quantas são estas habilidades? Balboni (2002, p. 114) acrescenta às quatro habilidades canônicas (compreender, falar monologo, ler e escrever) outras nove habilidades integradas:

1. Saber dialogar;

2. Saber parafrasear (oralmente e por escrito);

3. Saber resumir (oralmente e por escrito);

4. Saber anotar;

5. Saber escrever por ditado;

6. Saber falar baseando-se em roteiro escrito;

7. Saber traduzir por escrito;

8. A interpretação ou tradução oral;

9. Saber traduzir impromptu.

Se a tradução, conforme Balboni (2002), é uma das habilidades que um estudante de LE deveria dominar, nos perguntamos, ao contrário do que afirma a maior parte dos linguistas já há meio século, por que não considerá-la também uma técnica didática adequada para favorecer a aquisição de uma língua, para diminuir o filtro afetivo, para favorecer uma maior autonomia e também uma maior competência metalinguística, pragmática e cultural?

Existem teóricos que consideram, por vários motivos, não somente possível, mas até necessária uma reabilitação do uso da tradução em sala de aula. Harbord (1992), retomando as palavras de Atkinson, lembra justamente como o hábito de traduzir na própria língua seja a estratégia preferida pelos estudantes, um fenômeno natural e inevitável no processo de aprendizagem de uma LE:

[...] os alunos inevitavelmente (e mesmo inconscientemente) farão uma tentativa de igualar a estrutura da língua estrangeira ou um item lexical com seu correlato mais próximo ou o mais comum na língua materna, independentemente de haver ou não a oferta ou a permissão do professor para traduzir. (HARBORD, 1992, p. 351) ${ }^{8}$

\footnotetext{
${ }^{8}$ [...] learners will inevitably (and even unconsciously) attempt to equate a target language structure or lexical item with its closest or most common correlate in the mother tongue, regardless of whether or not the teacher offers or 'permits' translation.
} 
Considera-se então que esta tendência natural deva ser estimulada, e não contrastada, com exercícios e técnicas apropriadas. Para Harbord (1992), assim como para todos os autores citados e que se citarão mais adiante, é importante destacar e deixar bem claro que não se pretende fazer uma apologia da tradução, mas simplesmente justificar o seu uso em algumas situações específicas.

Uma segunda vantagem do uso da tradução, e então da LM em sala de aula, é que permite uma utilização eficiente do tempo disponível, ou seja, do tempo necessário para explicar um assunto. Em outras palavras, segundo Harbord (1992) e Atkinson (1993), muitos docentes julgam com razão a tradução válida em termos comunicativos, particularmente, em três situações específicas:

1. Na comunicação docente-discente;

2. Na relação docente-discente;

3. Na aprendizagem.

$\mathrm{Na}$ primeira categoria seriam mais evidentes as vantagens do uso da tradução, não somente por que facilita a passagem das mensagens linguísticas, mas até porque permite economizar tempo em sala de aula. Atkinson (1987) considera esta última uma das principais razões a favor do uso da LM. Algumas das estratégias sugeridas pelo autor para facilitar o andamento da aula são:

- Explicar o significado de uma palavra mediante a tradução;

- Controlar a compreensão de uma estrutura da LE na LM;

- Permitir ou estimular os estudantes para dar a tradução de uma palavra como controle de sua compreensão;

- Elicitar o vocabulário dando o equivalente na LM;

- Dar instruções que dizem respeito a uma atividade, na LM, facilitando a comunicação entre docente e estudante.

Essas estratégias estimulariam a reflexão sobre os mecanismos que a tradução de uma palavra em um determinado contexto implica, tornando os estudantes mais conscientes e ajudando-os a compreender que o que funciona numa língua não necessariamente funciona em outra: 
[...] a tradução deve ser usada para provocar discussão e especulação, para desenvolver a clareza e a flexibilidade do pensamento, e para nos ajudar a aumentar a nossa própria consciência e aquela dos nossos alunos acerca da interação inevitável entre a língua materna e a língua-alvo, que ocorre durante qualquer tipo de aquisição de língua. (HARBORD, 1992, p. 355$)^{9}$

Existem, porém, para outros teóricos, resistências de tipo ideológico e cultural ao uso da tradução e da LM em sala de aula. Elsa Roberts Auerbach indica que a recusa por parte de muitos docentes de usar a LM seria um reflexo da posição de superioridade da classe dominante e uma forma de manter o seu poder. A autora ressalta que ainda que existam motivos de tipo pedagógico, esta resistência ao uso da tradução e da LM, “[...] repousa em suposições não-examinadas, se origina na agenda política do grupo dominante, e serve para reforçar as relações de poder existentes" (AUERBACH, 1993, p. 12). ${ }^{10}$

Outras argumentações, porém, parecem mais convincentes para explicar a 'caça às bruxas' em relação ao uso da tradução em sala de aula. A autora sustenta, de forma partilhável, que foi imposta, em decorrência do amplo descrédito sofrido pelo Método da Gramática e da Tradução, uma atitude extrema que levou para a imediata e total exclusão da tradução das aulas de LE.

Muitos pesquisadores, docentes e estudantes, puderam constatar, ao contrário, em suas atividades, que, quando usada de forma apropriada, a tradução proporciona resultados positivos. É o caso de Costa (1988). Para este último, devese rever a política do ensino das línguas, pois

uma concepção mais ampla, mais cultural e crítica pode colocar a tradução como um dos meios mais eficientes de se estar permanentemente atento às diferenças em relação à língua (e à cultura) estrangeira. Contrariamente ao que se supõe, este procedimento pode ser muito mais eficaz porque revela, de maneira mais clara, as dificuldades e pode facilitar a sua superação. (1988, p. 283)

\footnotetext{
${ }^{9}$ [...] translation it should be used to provoke discussion and speculation, to develop clarity and flexibility of thinking, and to help us increase our own and our students' awareness of the inevitable interaction between the mother tongue and the target language that occurs during any type of language acquisition.

${ }^{10}[\ldots]$ it rests on unexamined assumptions, originates in the political agenda of the dominant group, and serves to reinforce existing relations of power.
} 
O nível dos estudantes condiciona fortemente um uso adequado da tradução. Se traduzir é inevitável nos estágios iniciais da aprendizagem - pois, como se escreveu em outro artigo (ROMANELLI, 2003), nestas etapas os discentes usam a gramática da LM como estratégia, é aconselhável, porém, usá-la somente para compensar o escasso conhecimento da LE; enquanto, em níveis mais adiantados, revela-se um ótimo meio de aprofundamento das estruturas lexicais e gramaticais, favorecendo desta forma a aprendizagem autônoma.

Talvez, querendo encontrar uma causa possível, a ideia de que o conhecimento da LM influenciaria negativamente a aprendizagem da LE pode ter limitado o uso da tradução em sala de aula durante certo período de tempo. Como se escreveu no artigo, $O$ ensino/aprendizagem de pronomes do italiano (Interferência na interlíngua do falante do Português Brasileiro), a concepção, de acordo com a qual as dificuldades de aprendizagem da LE dependiam da interferência da LM, remonta aos anos 1960:

Acreditava-se que as diferenças entre a $L M$ e a LE $e$ o conhecimento da LM que o sujeito tinha interferissem na aprendizagem de LE, e que, quando a $L M$ e a LE fossem similares, a LM ajudasse à aquisição de LE. Esse processo era chamado de Language transfer. Em caso de semelhanças entre $L M$ e LE, a transferência funcionaria positivamente; enquanto em caso de diferenças, funcionaria negativamente. Com o objetivo de prever os possiveis erros dos aprendizes, foi desenvolvida a Análise Contrastiva. (ROMANELLI, 2003, p. 42)

A interferência da LM na aprendizagem de uma LE foi posta em cheque no fim dos anos 1960 e perdeu de importância: foi quando a Análise Contrastiva foi incorporada na teoria cognitiva e foi demonstrado que vários fatores, além da estrutura da LM, contribuíam para criar uma interferência; fatores como as diferenças individuais dos estudantes (como citado cima), o papel do input e das estratégias cognitivas adotadas pelos próprios discentes. Os discentes, conforme esta concepção, selecionariam então os estímulos conforme critérios que já possuíssem internamente: o fato de ter já aprendido uma língua, a competência linguística previa (da LM e/ou de outras) e as habilidades metalinguísticas; todos os elementos sobre os quais, como se virá mais adiante, a tradução pode interferir positivamente.

Widdowson (1979) defende o uso da tradução, sobretudo, quando uma LE é estudada para fins específicos (instrumentais). Até nos níveis mais avançados, a 
tradução pode ser utilizada, mas somente mediante exercícios que não envolvam a estrutura gramatical de superfície, mas sim aquela de nível profundo, como quando si deseja estabelecer uma equivalência semântica ou pragmática entre as duas línguas. Mediante essas práticas, Widdowson destaca que a aula de LE se tornaria mais rica, fazendo com que os discentes percebam que as línguas utilizam meios diversos para expressar a mesma informação. Um uso adequado da tradução permitiria um confronto cultural mais profundo entre as duas línguas dando ao aluno um maior domínio da cultura de chegada.

Costa (1988) sugere diversos usos da tradução conforme o grau de proximidade entre a LM e a LE. É evidente que o docente de línguas românicas, ao ensinar a um estudante brasileiro, poderá fazer um uso mais específico da tradução em relação a um docente de línguas germânicas. De fato, quanto maior for a diferença entre as estruturas gramaticais e lexicais das duas línguas, muito mais necessário será o uso frequente da tradução nos níveis iniciais.

Deve-se, além disso, distinguir entre tradução oral e escrita. A primeira, afirma Costa, é um meio direto e eficaz para explicar o significado das palavras quando não é possível fazer diversamente e ajuda a verificar as lacunas do aluno que poderiam ficar despercebidas. Nos níveis mais avançados, a tradução oral pode tornar-se útil para desenvolver as capacidades de intérprete do discente (cfr. as habilidades mencionadas anteriormente por Balboni).

No que diz respeito à modalidade escrita, a tradução é uma técnica útil para verificar a competência do aluno e pode tornar-se necessária para verificar a sua compreensão de vocabulário, sintaxe, expressões idiomáticas e o uso de diferentes registros. Um exercício muito interessante, sempre no âmbito da língua escrita, é examinar várias traduções e compará-las entre elas pedindo aos alunos para justificar os critérios seguidos.

Para Costa (1988), finalmente, a tradução seria uma das formas mais adequadas para conhecer a estrutura de um texto e a sua utilização, além de ser um meio eficaz para desvelar os limites e as características do código linguístico materno. 


\section{A evidência da prática: algumas sugestões para o uso da tradução em sala de aula}

Costa (1988) não é o único defensor do uso da tradução em uma sala de aula de LE: Rinvolucri, julga que "[...] usar a língua materna de uma forma criteriosa e altamente técnica, na sala de aula de EFL permite que a plenitude da inteligência linguística do aluno seja posta em jogo [...]" (apud DAJANI, 2002, p. 65). ${ }^{11}$

Atkinson (1987, p. 241) faz uma lista de todos os usos apropriados da LM em uma sala de aula de LE:

1. Elicitar a língua: "Como se diz ' $X$ ' na LE”;

2. Verificar a compreensão;

3. Dar instruções complexas nos níveis iniciais;

4. Cooperar em grupos: os estudantes comparam e corrigem as respostas dos exercícios ou das tarefas na LM;

5. Explicar a metodologia adotada em sala de aula nos níveis iniciais;

6. Esclarecer um assunto linguístico recém-abordado;

7. Verificar o sentido: no caso em que os estudantes escrevam ou digam algo na LE que não faça sentido, devem tentar traduzir a expressão na LM para dar-se conta do seu erro;

8. Medir o domínio de formas e significados;

9. Desenvolver estratégias perifrásticas: quando os alunos não sabem como dizer algo na LE, devem encontrar formas alternativas para dizer a mesma coisa na LM, de modo que seja mais fácil traduzi-la. ${ }^{12}$

Já Auerbach (1993), em seu artigo, Reexamining English Only in the ESL Classroom, sugere as seguintes ocasiões para utilizar a LM:

\footnotetext{
${ }^{11}$ [...] using the mother tongue in a judicious and highly technical way in the EFL classroom allows the fullness of the learner's language intelligence to be brought into play [...].

${ }^{12}$ Adaptado de The Mother Tongue in the Classroom de David Atkinson (1987).
} 
- Discutir o conteúdo programático e a metodologia da aula (proporciona um papel mais ativo do discente na organização da aula, em consonância com as tendências atuais da Glotodidática a favor de uma maior autonomia);

- Organizar a aula;

- Fazer a análise linguística;

- Apresentar as leis que governam a gramática, a fonologia, a morfologia e a ortografia;

- Discutir assuntos interculturais;

- Dar instruções e sugestões;

- Explicar os erros e avaliar a compreensão.

Benucci (1994), diferentemente de outros teóricos, considera vantajoso utilizar a tradução para a possibilidade de refletir, em um nível contrastivo/comparativo, nas relações internas entre as várias formas e as várias estruturas das duas línguas envolvidas, colocando em evidência as diferenças e os paralelismos. A Análise Contrastiva, a seu ver, poderia facilitar, ao menos nos níveis mais avançados, a reflexão sobre as relações da LE com outras línguas e outras culturas, em uma dimensão sincrônica e temporal. Não obstante a Análise Contrastiva não possua mais a mesma relevância que tinha no passado, pode de qualquer forma ser bem utilizada dentro da perspectiva comunicativa. Benucci aponta que no âmbito da análise dos erros, a falta de um transfert positivo, isto é, o desrespeito das regras da LM parecidas com as da LE, mereceria uma maior atenção por parte do docente.

Atkinson (1993) também aborda a questão do uso da tradução em sala de aula e fornece exemplos práticos aos docentes no livro, Teaching Monolingual Classes. Na opinião do estudioso, a teoria que considera inoportuno usar mais que $1 \%$ da LM em uma sala de aula de LE não sempre se revela certa. Aprender uma LE, sobretudo nos primeiros níveis, é difícil e frustrante, e, nestes casos, o uso de apenas $1 \%$ da LM pode contribuir com o aumento dessa frustração, enquanto que um uso maior da LM pode ter efeitos positivos: “[...] Para muitos alunos (em particular os adultos e adolescentes), o uso ocasional da L1 dá a eles a oportunidade 
para mostrar que são pessoas inteligentes e sofisticadas" (ATKINSON, 1993, p. 1314). ${ }^{13}$

Um uso equilibrado da LM depende, para Atkinson, de vários fatores:

- Da experiência prévia dos alunos (se estão, isto é, acostumados ao uso da LM em sala de aula ou não);

- Do nível de conhecimento da língua (quanto mais avançado o nível menos frequente será o uso da LM);

- Do nível do curso (quanto mais familiar a relação entre docente e discente, mais fácil será a condução da aula somente na LE);

- Do nível da aula (a LM pode não revelar-se útil em um nível avançado, mas pode tornar-se útil em um nível inicial).

Mas quais são, finalmente, os benefícios do uso da tradução em sala de aula? Atkinson (1993) propõe alguns:

- A tradução força os alunos a refletir sobre o significado das palavras dentro de um contexto, e não somente a manipular formas gramaticais de maneira mecânica; coisa que acontece em muitos exercícios estruturais;

- O uso da tradução permite aos alunos pensar 'comparativamente'. A comparação entre as duas línguas os leva a ter uma consciência maior acerca das diferenças e a evitar grande parte dos erros mais comuns na LE;

- As atividades que envolvem a tradução podem ser usadas para estimular os estudantes a assumir riscos e a não tentar evitá-los. É uma forma para estimular os alunos a forçar sua competência o máximo possível para superar suas dificuldades: eles devem esforçar-se para dizer determinada coisa em outra língua usando todas as estruturas linguísticas, gramaticais e semânticas que já conhecem;

- A atividade tradutória, ainda que breve, pode contribuir para dar novo ritmo à aula;

- A tradução é uma atividade da vida real. Em várias ocasiões da vida profissional, ou pessoal, os alunos poderão desfrutar dessa habilidade.

\footnotetext{
${ }^{13}$ [...] for many learners (in particular adults and teenagers), occasional use of the L1 gives them the opportunity to show that they are intelligent, sophisticated people.
} 
Em suma, para que a tradução seja uma técnica realmente valiosa, o docente deve motivar os estudantes com atividades interessantes, utilizando material estimulante. Apresentam-se a seguir algumas propostas práticas selecionadas por Atkinson (1993):

1) Corrigir uma tradução errada: o docente prepara textos com palavras traduzidas de forma errada para que os alunos as analisem e corrijam. Esta atividade pode ser feita com a tradução de expressões comuns, até em níveis mais avançados, com a finalidade de analisar aspectos específicos da gramática. Este tipo de atividade ajuda aos alunos a focalizarem mais intensamente algumas áreas críticas;

2) Consolidar mediante traduções: este tipo de exercício dá ao aluno mais confiança em uma área específica da gramática, no vocabulário ou no uso de qualquer função da língua que tenha estudado. Para ilustrar esta estratégia, o docente pode escrever um texto na LM, cuja tradução na LE inclua certo numero de exemplos que testem uma área específica de dificuldade. É importante que o texto seja o mais realista possível; o objetivo deste tipo de atividade é ajudar os estudantes a exercitarem-se em um aspecto específico da língua objeto de estudo;

3) Comparar versões diferentes (dadas pelo docente): este tipo de atividade pode estimular os estudantes a considerar o contexto, cuidando do significado social (ou melhor, pragmático) das palavras e das frases escolhidas;

4) Comparar versões diferentes (escritas pelos estudantes): os textos preparados pelo professor serão traduzidos pelos alunos, em duplas. Cada um traduz na LM um trecho que, depois, o colega passa para a LE, comparando no fim as versões, na LE, dos dois textos em que trabalharam. Esta atividade ajuda os alunos a desenvolver as habilidades da tradução e a perceber as diferenças entre a LM e a LE;

5) Resumir a tradução: os alunos preparam, em casa, a tradução de um trecho de um livro e cada um apresenta, na sala, oralmente, um parágrafo, além de dar uma síntese daquilo que leu; 
6) Interpretar na sala de aula: o docente inventa um diálogo entre um falante da LE e outro da LM. Os estudantes devem atuar como intérpretes, enquanto o docente grava o diálogo. Então, os alunos escutam o diálogo gravado e o anotam. Este tipo de atividade permite aos estudantes trabalhar como intérpretes, nas duas línguas, praticando, ao mesmo tempo, uma atividade real.

\section{Conclusão}

Neste artigo, tem-se considerado algumas das razões que levaram à exclusão da tradução das salas de aula de língua estrangeira; razões não somente fundamentadas em presumidas teorias pedagógicas, mas também em preconceitos ideológicos e em estereótipos didáticos pouco comprovados. A análise destas razões foi conduzida levando em consideração alguns estudos recentes publicados sobre o assunto na Itália, no Brasil, na Inglaterra e nos Estados Unidos. Observou-se como, segundo conceituados teóricos, seja necessário retomar em consideração o uso da tradução como técnica didática enquanto muito apropriada para a aprendizagem de uma LE. Destacou-se também em várias ocasiões que não se pretendia fazer uma apologia da tradução -, pois se usada de forma excessiva e inapropriada não se torna muito produtiva a fins didáticos -, mas mostrar como existem, didaticamente falando, algumas vantagens, em geral, raramente consideradas por motivos pelo menos duvidosos. Com este trabalho, não se pretendia oferecer nenhuma verdade definitiva, mas somente contribuir com a reavaliação da tradução e com a reabertura de um debate que foi esquecido demasiadamente cedo.

\section{Referências}

ATKINSON, David. The mother tongue in the classroom: a neglected resource? ELT Journal, v. 41, n. 4, October, 1987, p. 241-247.

. Teaching monolingual classes. Essex: Longman Group UK Limited, 1993. 
AUERBACH, Ernest. Reexamining English only in the ESL classroom. Tesol Quarterly, v. 27, n. 1, spring 1993, p. 9-30.

BALBONI, Paolo. Tecniche didattiche per l'educazione linguistica. Italiano, lingue straniere, lingue classiche. Torino: Utet, 1998.

BALBONI, Paolo. Le sfide di Babele: Insegnare le lingue nelle società complesse. Torino: Utet, 2002.

BENUCCI, Antonella. La grammatica nell'insegnamento dell'italiano a stranieri. Roma: Bonacci Editore, 1994.

COSTA, Walter Carlos. Tradução e ensino de línguas. In: BOHN H. I.; VANDRESEN, P. Tópicos de Lingüística Aplicada ao ensino de línguas estrangeiras. Florianópolis: Editora da UFSC, 1988, p. 282-291.

DAJANI, Jabr. Using mother tongue to become a better learner. MET, v. 11, n. 2 , 2001, p. 65-67.

HARBORD, John. The use of the mother tongue in the classroom. ELT Journal, v. 46, n. 4, October, 1992, p. 350-355.

RANCIÈRE, Jacque. $O$ mestre ignorante. Cinco lições sobre a emancipação intelectual. Belo Horizonte: Autêntica, 2005.

ROMANELLI, Sergio. O ensino/aprendizagem de pronomes do italiano: interferência na interlíngua do falante do português brasileiro. Desempenho, UnB, 2003, p. 41-50.

TITONE, Renzo. Glottodidattica: un profilo storico. Bergamo: Minerva Italica, 1982.

WIDDOWSON, Henry. The deep structure of discourse and the use of translation. In: BRUMFIT, C. J.; JOHNSON, K. (Eds.). The communication approach to language teaching. Oxford: Oxford University Press, 1979. (fotocopia sem número das páginas). 